Vol.60: e17160244, January-December 2017 http://dx.doi.org/10.1590/1678-4324-2017160244 ISSN 1678-4324 Online Edition
BRAZILIAN ARCHIVES OF

BIOLOGY AND TECHNOLOGY

AN INTERNATIONAL JOURNAL

\title{
Apoptosis and Histopathology of the Heart after Renal Ischemia-Reperfusion in Male Rat Running title: Ischemia- Reperfusion Injury
}

\author{
Alireza Alihemmati ${ }^{1}$, Hadi Yousefi ${ }^{2 *}$, Naser Ahmadiasl ${ }^{2}$, Parisa Habibi ${ }^{2}$. \\ ${ }^{1}$ Tabriz University of Medical Sciences - Department of Anatomy and Histology, Faculty of Medicine, Tabriz, Iran; \\ ${ }^{2}$ Tuberculosis and Lung Disease Research Center, Tabriz University of Medical Sciences, Tabriz, Iran
}

\begin{abstract}
Ischemia-reperfusion injury was seen in strokes, myocardial infarctions, acute kidney injury, mesenteric ischemia, liver and systemic shock. Renal ischemia-reperfusion is more importance in the setting of kidney transplantation that affects distant organs. In this study forty Male Albino Wistar rats (200-250g) were randomly divided in four group (n=10) including control, sham operation group, nephrectomy and IRI group. All rats anesthetized with intraperitoneal injection of ketamine $(50 \mathrm{mg} / \mathrm{kg})$ and xylazine $(10 \mathrm{mg} / \mathrm{kg})$ and maintained the core body temperature at approximately $37^{\circ} \mathrm{C}$. For inducing IRI group, it was performed right nephrectomy, and in continuing, the left kidney pedicle occluded to $45 \mathrm{~min}$ via nontraumatic microvascular clamp for making ischemia that followed 24 hours reperfusion. TUNEL assay was used to detect the cardiac apoptotic cells. Hematoxylin-Eosin staining and periodic acid-Schiff (PAS) procedure was used to histopathological assessment and glycogen accumulation respectively. There was more heart damage at 24 h reperfusion in IRI group. Renal IRI group showed myocardial degeneration, necrosis and increasing connective tissue in myofibril. There were apparent hypertrophy and swelling of myofibril, fragmentation and vacuolization of sarcoplasm. In addition, it was shown elevated apoptotic cell at 24 hours reperfusion in renal IRI group than sham group. There were increases of glycogen accumulation in cardimyocyte of renal IRI group. Our findings suggest that renal IRI-induced cardiac damage, accompanied by an accumulation of glycogen granules, induced apoptosis and histological changes in cardiomyocytes.
\end{abstract}

Key words: Renal Ischemia-reperfusion injury, glycogen accumulation, apoptosis, heart, rat

\footnotetext{
*Author for correspondence: hadi2f006@yahoo.com
} 


\section{INTRODUCTION}

Ischemia-reperfusion injury was seen in strokes, myocardial infarctions, acute kidney injury, mesenteric ischemia, liver shock and systemic shock. Both clinical and experimental investigations revealed that transplant IRI has deleterious longand short-term effects including augmented incidents of chronic allograft damage and acute rejection (1). Renal ischemia-reperfusion (IRI) is a main cause of acute kidney injury (AKI), possibly development to chronic renal disease that may leads to death in patients.

Pathologically, ischemic AKI is characterized by lethal and sublethal damages in kidney tubules, especially the proximal tubules of the nephrons $(2,3)$.

Cell death in kidney tubules in the forms of both necrosis and apoptosis is identifying in animal models as well as the kidney of AKI patients. Interestingly, renal tubules have the ability to repair of itself, and when the repairs is not completed, fibrosis was developed and contributing to failure of the kidney function and chronic deficiency (4-6). Renal ischemia-reperfusion injury is general organ dysfunctions in clinical practice, which can not only lead to alterations in kidney function, but also causes some organ dysfunctions. It can induce multiple organ dysfunctions including pancreatic trauma, lung, liver injury and cardiac dysfunction (7-10).

Among them, the cardiac tissue is the most sensitive to renal ischemia-reperfusion injury, pathological and physiological changes. Recently, more researches were performing to study the effect of renal ischemia-reperfusion on other organs, as well as the influence of renal ischemia reperfusion on heart tissue. Renal IRI can cause heart damage, which has confirmed by researches. However, in these investigations, it performed bilateral renal ischemia-reperfusion on animal's model that was happen in many types of shock. However, the effects of unilateral renal ischemia-reperfusion that may happens in renal transplantation on cardiac injury as a distant organ not yet investigated.

The present study designed to investigate the effects of renal ischemia reperfusion injury, similar to kidney transplantation models, on apoptosis, tissue injury and glycogen accumulation in cardiomyocyte of mal rat.

\section{MATERIAL AND METHODS}

\section{Animals}

In this study, forty male Albino-Wistar rats with weighting 200-250g were purchase from the experimental animal research center, Tabriz University of medical sciences, Tabriz, Iran. All rats were housed at room temperature about $21 \pm 2{ }^{\circ} \mathrm{C}$, humidity about $60 \pm 5 \%$ with a $12-12$ h light-dark cycle. They had free access to water and food. This study was approved by the University Ethics Committee.

\section{Surgery and Experimental protocol}

Rats were divided in four groups $(n=10)$ including control group (without any procedure), sham surgery (that was performed only laparotomy), nephrectomy (that right kidney was removed), and IRI groups (right nephrectomy + left IRI). Animals were anesthetized with intraperitoneal injection of ketamine $(50 \mathrm{mg} / \mathrm{kg})$ and xylazine $(10 \mathrm{mg} / \mathrm{kg})$, and placed on a homeothermic table to preserve core body temperature at $37^{\circ} \mathrm{C}$ approximately. In IRI group, it was performed right nephrectomy and in continuing after a week recovery, the left kidney pedicle occluded to $45 \mathrm{~min}$ via nontraumatic microvascular clamp (S\&T, Canada) for induction of ischemia which followed by 24 hours reperfusion. At the end of $45 \mathrm{~min}$ ischemia, clamp was removed slightly and the left kidney was observed for 5 min to make sure reflow 
process. Then, sterile saline $\left(1 \mathrm{ml}, 37^{\circ} \mathrm{C}\right)$ was injected intraperitoneally and the incision was closed. The animals then returned to separate cages and allowed to recover. In addition, animals kept well hydrated with warm sterile saline and maintained at body temperature $\left(\sim 37^{\circ} \mathrm{C}\right)$. At the end of reperfusion phase, the hearts were isolated to be used for histological and apoptotic assays.

\section{TUNEL assay}

TUNEL (terminal deoxynucleotidyl transferase-mediated dUTP nick end labeling) kits (Roche) used to revealing of apoptosis in heart tissue after renal Ischemiareperfusion. After fixation in $10 \%$ formalin, the heart tissue was embedded and sectioned and then detected apoptotic cell according to the instructions of TUNEL kit. The TUNEL-positive cells were determined. Ten fields of vision selected randomly to assay the apoptotic cells. Apoptotic positive cells were scored (-) none, $(+)$ mild, (++) moderate, and (+++) severe damage (11).

\section{Histopathological assessment}

For histopathological analyses, isolated hearts fixed in $10 \%$ formalin. The samples dehydrated with ethanol and embedded in paraffin. Sections with $4 \mu \mathrm{m}$ thickness were cut and stained with Hematoxylin and Eosin (H-E) to evaluate tissue injury. For evaluation of glycogen accumulation, the sections stained with periodic acidSchiff (PAS) procedure. Histological changes scored on a 4-point scale: (-) none, (+) mild, $(++)$ moderate, and $(+++)$ severe damage.

\section{RESULTS}

\section{Kidney IRI Induces heart muscle Apoptosis}

Apoptosis was apparent in the heart by the TUNEL staining $24 \mathrm{~h}$ after renal ischemia. More TUNELpositive cells observed in the heart sections harvested after renal ischemia. (Fig. 1\& table 1). Furthermore, TUNEL positive cells were not present following sham operation or nephrectomy groups. To avoid of crowd, it was not presented control groups results, because of similarity in all results of sham and control groups in this paper. 


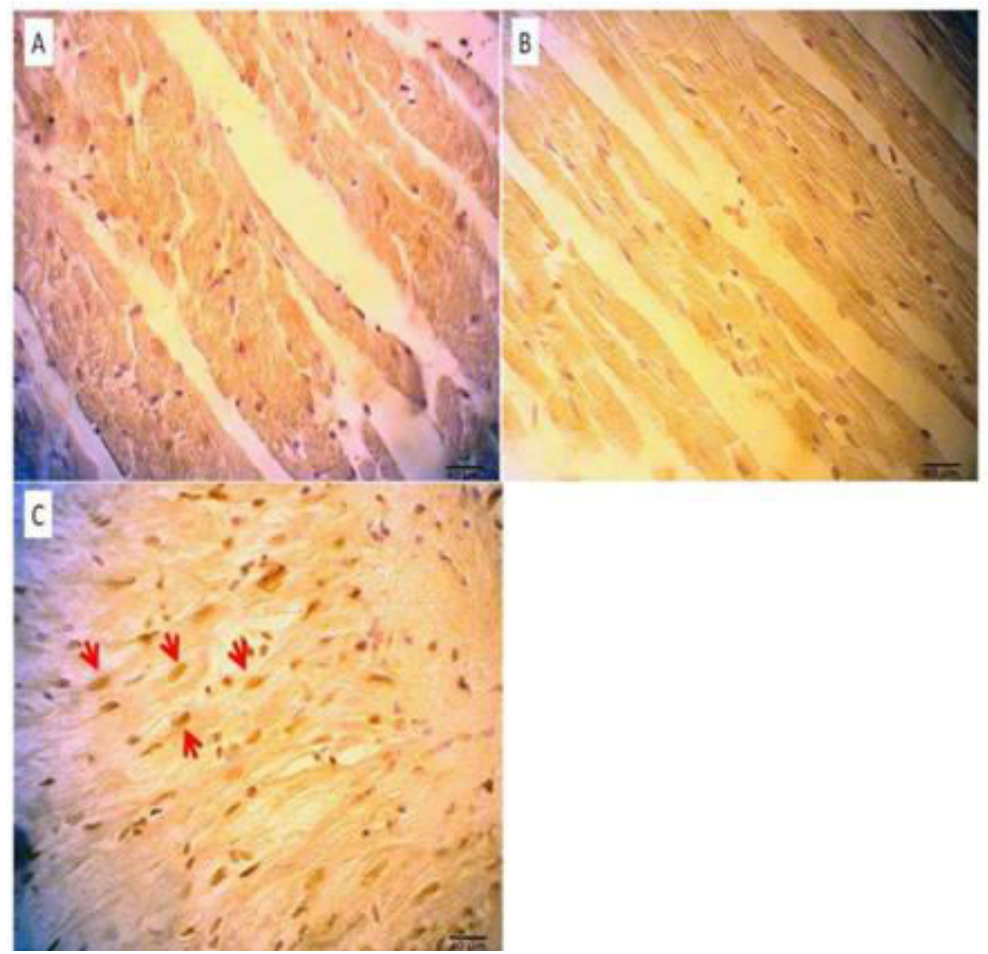

Figure 1. TUNEL staining: Cardiac myocyte apoptosis during renal ischemia-reperfusion injury. Cardiac microscopic micrographs (Magnification $\times 40$ ) obtained $24 \mathrm{~h}$ following 45-min renal ischemia with TUNEL (A) sham, (B) nephrectomy, (C) renal ischemia-reperfusion group. Red arrow demonstrates cardiac myocyte apoptosis in this model of renal IRI. Bar $(\mathrm{A}, \mathrm{B}, \mathrm{C})=40 \mu \mathrm{m}$.

Table 1. Evaluation of TUNEL positive cardiac myocyte.

\begin{tabular}{lll}
\hline Groups & Sham & Right \\
& Nephrectomy
\end{tabular}

TUNEL positive cells $\quad$ - / Rarely $+\quad+\quad+++$

A minimum of 10 fields for each heart slide were examined and assigned for severity of changes using scores on a scale of: $(-)$

none, $(+)$ mild, $(++)$ moderate, and $(+++)$ severe damage. $(\mathrm{n}=10$ for each group)

\section{Kidney IRI induces histological changes}

We examined the effects of renal ischemia reperfusion on the cardiac injury of rats. Routine H-E staining revealed irregularities in heart muscles and increasing connective tissue in myofibril. In addition, hypertrophy, swelling of myofibril, Fragmentation and vacuolization of sarcoplasm observed in IRI group than sham group. Increasing the spaces between fibers, the extremely acidophilic of cytoplasm, polymorphic nucleic, pyknotic nuclei, broad and spread hemorrhage and degeneration of myofibril observed in IRI group (see in Fig $2 \&$ table 2). 


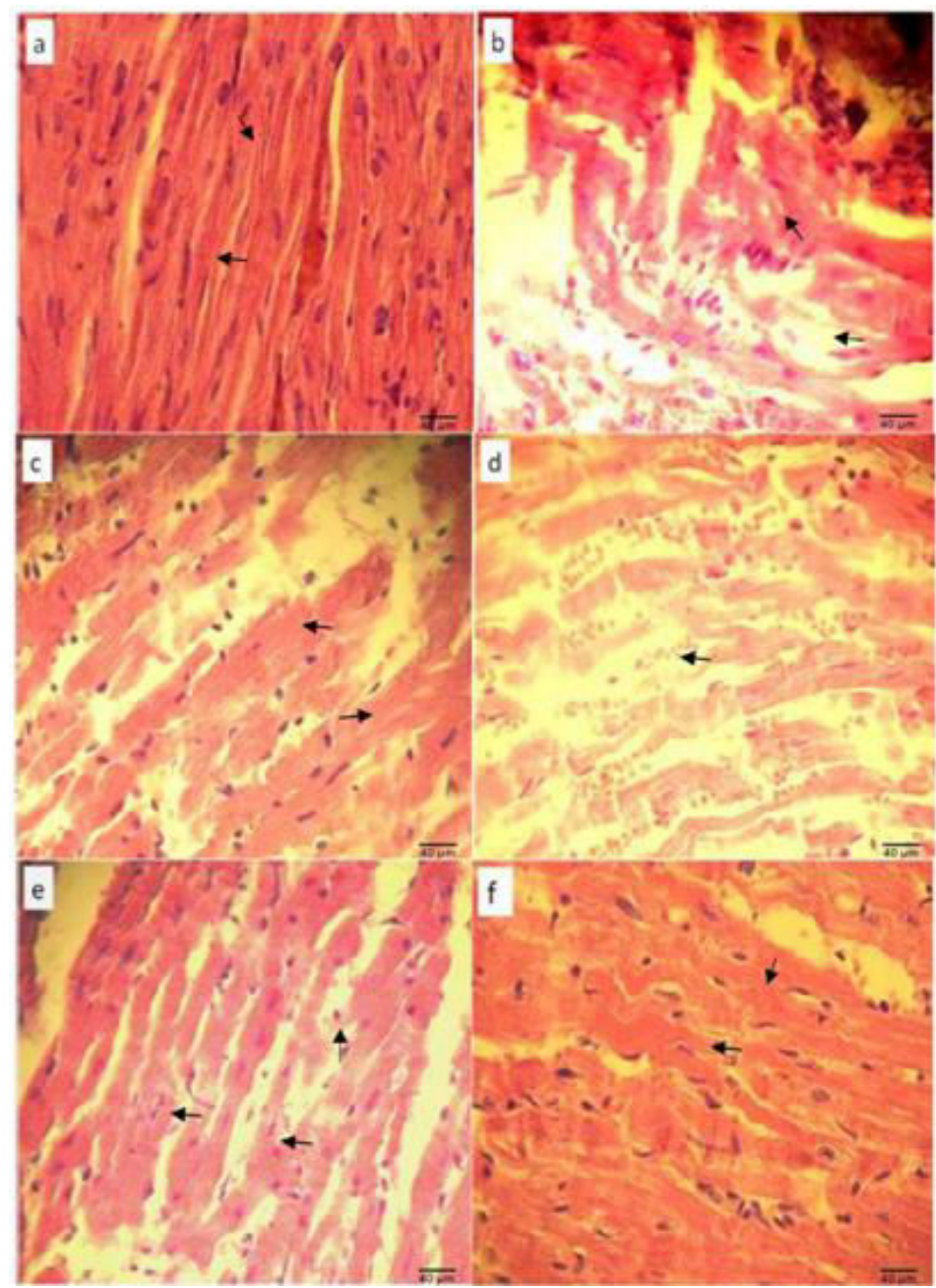

Figure 2. H-E assay: (a) sham: Striated lines and interstitial sheets are clear (Magnification $\times 40)$. (b-e) ischemiareperfusion that (b) irregularities in heart muscles and increasing connective tissue (Magnification $\times 40)$, (c) hypertrophy and swelling of myofibril, Fragmentation and vacuolization of sarcoplasm (Magnification $\times 40)$, (d) Broad and spread hemorrhage and degeneration of myofibril (Magnification $\times 40$ ). (e) Cardiomyocyte destruction, the extremely acidophilic cytoplasm, polymorphic nucleus and pyknotic nuclei (Magnification $\times 40$ ), and nephrectomy groups with (f) less shrinkage in myofibril (Magnification×40). Bar (a-f) $=40 \mu \mathrm{m}$.

Table 2. Histological changes in the heart after $24 \mathrm{~h}$ renal ischemia reperfusion (H\&E)

\begin{tabular}{|c|c|c|c|c|c|c|}
\hline Groups & $\begin{array}{l}\text { irregulariti } \\
\text { es } \\
\text { in heart } \\
\text { muscles }\end{array}$ & $\begin{array}{l}\text { hypertrop } \\
\text { hy } \\
\text { and } \\
\text { swelling } \\
\text { of } \\
\text { myofibril }\end{array}$ & $\begin{array}{l}\text { Fragmentat } \\
\text { ion } \\
\text { and } \\
\text { vacuolizati } \\
\text { on } \\
\text { of } \\
\text { sarcoplasm }\end{array}$ & $\begin{array}{l}\text { hemorrhage } \\
\text { and } \\
\text { degeneration } \\
\text { of } \\
\text { myofibril }\end{array}$ & $\begin{array}{l}\text { shrinkage i } \\
\text { myofibril }\end{array}$ & $\begin{array}{l}\text { n increasing } \\
\text { connective } \\
\text { tissue }\end{array}$ \\
\hline Sham & - & - & - & - & - & - \\
\hline $\begin{array}{l}\text { nephrecto } \\
\mathrm{m} \\
\mathrm{y}\end{array}$ & + & + & + & - & + & - \\
\hline IR & +++ & +++ & +++ & +++ & +++ & +++ \\
\hline
\end{tabular}

A minimum of 10 fields for each heart slide were examined and assigned for severity of changes using scores on a scale of: $(-)$ none, $(+)$ mild, $(++)$ moderate, and $(+++)$ severe damage. $(\mathrm{n}=10$ for each group) 


\section{Kidney IRI Induces glycogen accumulation in cardiomyocyte}

PAS staining performed on heart tissue at $24 \mathrm{~h}$ following kidney IRI, sham and nephrectomy groups to evaluate glycogen accumulation in cardiomyocyte. Glycogen was accumulating in cardiac myocyte at $24 \mathrm{~h}$ following renal IRI (Fig. 3\& table 3). Furthermore, accumulation of glycogen was not present following sham operation or nephrectomy groups.

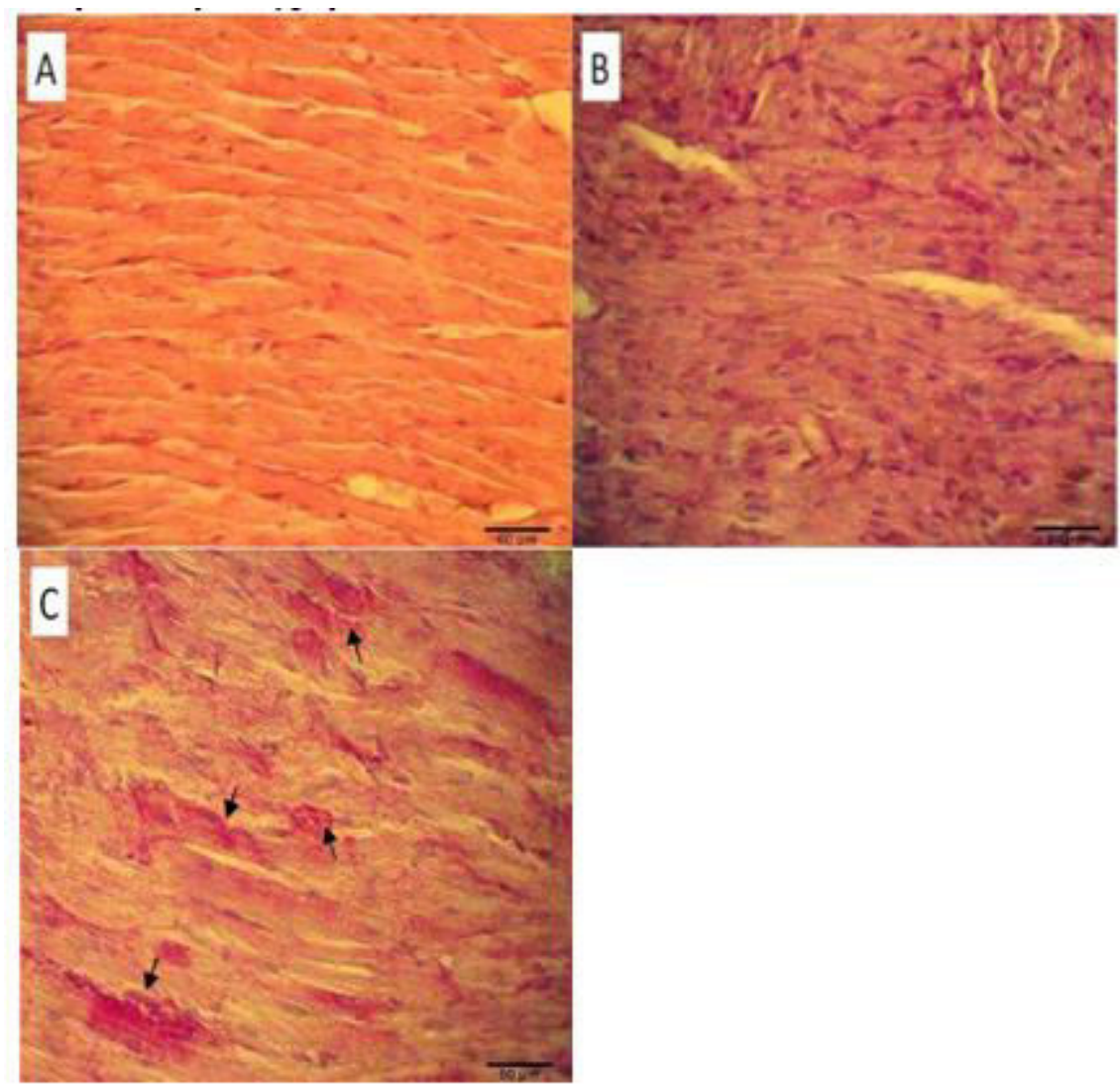

Figure 3. PAS assay: Cardiomyocyte glycogen accumulation after renal ischemia-reperfusion injury. Cardiac microscopic micrographs (Magnification $\times 40$ ) obtained $24 \mathrm{~h}$ reperfusion following 45-min renal ischemia with PAS (A) sham, (B) nephrectomy, (C) renal ischemia-reperfusion group. Bar (A,B,C)=50 $\mu \mathrm{m}$.

Table 3. Evaluation of glycogen accumulation in cardiac myocyte.

\begin{tabular}{llll}
\hline Groups & Sham & $\begin{array}{l}\text { Right } \\
\text { Nephrectomy }\end{array}$ & IRI \\
\hline & & \\
\hline $\begin{array}{l}\text { glycogen } \\
\text { accumulation }\end{array}$ & $-/$ Rarely ++ & +++ \\
\hline
\end{tabular}

A minimum of 10 fields for each heart slide were examined and assigned for severity of changes using scores on a scale of: $(-)$ none, $(+)$ mild, $(++)$ moderate, and $(+++)$ severe damage. $(\mathrm{n}=10$ for each group) 
Ischemia-Reperfusion Injury

\section{DISCUSSION}

IRI results in endothelial and leukocyte activation, production of reactive oxygen species, tubular cell death and release of inflammatory mediators, such as cytokines and chemokines (12). Ischemic reperfusion injury initiated by production of reactive oxygen species, which initially seems to be responsible for the generation of chemotactic activity for neutrophils. In reperfusion injury, a variety of cytokines and mediators may be responsible for priming neutrophils $(13,14)$. Ischemia reperfusion injury is a common cause for the progress of acute renal injury and is characterized by renal inflammation and tissue damage.

Necrosis leads to the release of molecular patterns which subsequently stimulate the innate immune system and trigger an immune response (15).Temporal expression of chemokines is an important factor in the regulation of kidney ischemia/ reperfusion injury. Beside their role in the activation and migration of inflammatory cells to locations of injury, chemokines are also involved in other processes such as angiogenesis, development and migration of stem cells (16). Besides the local damage caused by renal IRI, distant organs can also be affected $(9,10,17,18)$. Although many studies have performed to demonstrate the systemic effect of IRI, the mechanism is not well known. In this work, we used a rat model of unilateral renal ischemia injury after right nephrectomy, similar to kidney transplantation, to study distant injurious effects on the heart.

Apoptosis and tissue injury in the heart tissue of mal rat subjected to $45 \mathrm{~min}$ of renal ischemia. Then heart tissue studied at 24 hours after reperfusion. Our results indicated irregularities in heart muscles and increasing connective tissue in myofibril. In addition, hypertrophy and swelling of myofibril, Fragmentation and vacuolization of sarcoplasm was observed in IRI group that all of them indicated injury in the heart after renal IR.

Apoptosis has been proposed to be a main mechanism for many cell death in reperfused ischemic myocardium (19). It could be regulated by oxygen free radicals, cytokines such as TNF- $\alpha$ and IL-6, and neutrophil accumulation (20). Kidney IRI in mice initiates an early inflammatory response, which characterized by quick triggering of the transcription factors NF-kB in the lung. This was followed by TNF$\alpha$ expression in lung and accumulation of neutrophils by $4 \mathrm{~h}$ post injury. This connection of inflammatory cytokines in renal IRI-induced remote organ dysfunction has been corroborated by critical roles of cytokines in modulating the remote organ lung effects during AKI (21). Serum pro-inflammatory cytokines such as TNF- $\alpha$ levels increase significantly in renal IR (22). These circulatory inflammatory cytokines transferred to other organs such as lung (9) and probably heart, that may cause apoptosis in this tissues. Our results indicated that massive cardiomyocyte apoptosis at $24 \mathrm{~h}$ after renal IRI. TUNEL-positive nuclei identified in cardiac myocyte at $24 \mathrm{~h}$ following renal IRI.

Loss of cardiomyocytes believed to be important in the pathogenesis of congestive heart failure (CHF).

Study on transgenic models has shown that apoptosis alone can outcome in cardiac failure (23).The increase in cardiac apoptosis we observed after renal ischemiareperfusion than sham group. Renal ischemia was critical in the induction of apoptosis in cardiomyocytes, because TUNEL-positive cells found after $24 \mathrm{~h}$ of renal ischemia-reperfusion but not in right nephrectomy or sham group.

There are a few investigations addressing Renal-heart interactions. In transgenic sickle mice, bilateral kidney IR resulted in significant vascular congestion in the 
heart and increased serum amyloid Pcomponent (24). In addition, renal ischemiareperfusion in wild-type mice was increased cytokine expression in cardiomyocytes that leads to apoptosis of cardiomyocytes and impaired cardiac function (8). In one study, pancreatic isolated tissue from ischemic rats exhibited significant increase in histopathological destruction score, necrosis and marked increase in MDA and catalase enzyme. Bilateral renal ischemia for $45 \mathrm{~min}$ caused impairment of islets functions and histology. This might be due to deficiency of antioxidant capacity and induced lipid peroxidations in pancreatic tissues (7).

In another study, Campanholle et al was showed that TNF- $\alpha$ is overexpressed in both kidneys and lungs following bilateral renal ischemia reperfusion. In this study it was reported that proinflammatory mediators of IL- $1 \beta$ and TNF- $\alpha$ in serum significantly enhanced after renal ischemia reperfusion that all of them are transferred to the lung via the thoracic lymphatic duct (25). In the our previous study, we showed that unilateral renal ischemia reperfusion causes increase in TNF- $\alpha$ and decrease in Bcl-2 protein levels in lungs, and subsequently induces the lungs injury as a distant organ (9). These proinflammatory molecules can induce direct tissue damage and are also potent activators of leukocytes (14). In the present study it was seems that cytokines and chemokine's was reached to the heart as a distant organ and induced leukocyte activity and neutrophil infiltration which accompanied with tissue injury and apoptosis.

Cardiac neutrophil infiltration suggested by increased myeloperoxidase activity. Increased apoptosis was detected by TUNEL staining after bilateral renal IRI but not after bilateral nephrectomia (8). Evaluation of glycogen content in cardiac histological sections showed accumulation of glycogen granules in the IRI group, whereas the hearts tissue of sham surgery group were not shown glycogen granules. It was shown that glycogen deposition triggered apoptosis specifically in neuron via activation of apoptotic markers (26). Serum level of free radicals and proinflammatory cytokines were elevated in renal ischemia reperfusion (6). All of them caused to cell and mitochondrial injury that may impaired glycogen metabolism and its deposition in tissues. Glycogen functions as the secondary energy storage in long-term of animal cells. Glycogen synthase and glycogen phosphorylase are controlled the production and breakdown of glycogen respectively and the regulation of both enzymes is differentiated by great complexity with many factors (27-30). As well as, glycogen excess has been suggested to bring about structural and physiological impairments including change in $\mathrm{pH}$, ionic imbalance and a motivation of pathways leading to cardiomyocyte hypertrophic signaling (31).

\section{CONCLUSION}

This experiment revealed that renal IRI-induced cardiomyopathy, accompanied by an accumulation of glycogen granules and induced apoptosis and histological changes in cardiomyocytes.

\section{ACKNOWLEDGMENTS}

This study financially supported by Tuberculosis \& Lung Research Center of Tabriz University of Medical Sciences, Tabriz, Iran (Grant number: 90/2-1/6).

\section{REFERENCES}

\section{Tilney NL, Guttmann RD. EFFECTS OF INITIAL ISCHEMIA/REPERFUSION INJURY} ON THE TRANSPLANTED KIDNEY1. Transplantation. 1997;64(7):945-7. 
Ischemia-Reperfusion Injury

2. Bonventre JV, Yang L. Cellular pathophysiology of ischemic acute kidney injury. The Journal of clinical investigation. 2011;121(11):4210.

3. Sharfuddin AA, Molitoris BA. Pathophysiology of ischemic acute kidney injury. Nature Reviews Nephrology. 2011;7(4):189-200.

4. Chawla LS, Kimmel PL. Acute kidney injury and chronic kidney disease: an integrated clinical syndrome. Kidney international. 2012;82(5):516-24.

5. Venkatachalam MA, Griffin KA, Lan R, Geng H, Saikumar P, Bidani AK. Acute kidney injury: a springboard for progression in chronic kidney disease. American Journal of Physiology-Renal Physiology. 2010;298(5):F1078-F94.

6. Ahmadiasl N, Banaei S, Alihemmati A. Combination antioxidant effect of erythropoietin and melatonin on renal ischemia-reperfusion injury in rats. Iranian journal of basic medical sciences. 2013;16(12):1209.

7. Hussein A, Abd-Elkhabir A, Abozahra A, Baiomy A, Ashamallah SA, Sheashaa HA, et al. Pancreatic injury secondary to renal ischemia/reperfusion (I/R) injury: possible role of oxidative stress. Physiological Research. 2014;63(1):47.

8. Kelly K. Distant effects of experimental renal ischemia/reperfusion injury. Journal of the American Society of Nephrology. 2003;14(6):1549-58.

9. Yousefi H, Ahmadiasl N, Alihemmati A, Habibi P. Effect of renal ischemia-reperfusion on lung injury and inflammatory responses in male rat. Iranian journal of basic medical sciences. 2014;17(10):802.

10. Khastar H, Kadkhodaee M, reza Sadeghipour H, Seifi B, Hadjati J, Najafi A, et al. Liver oxidative stress after renal ischemia-reperfusion injury is leukocyte dependent in inbred mice. Iranian journal of basic medical sciences. 2011;14(6):534.

11. Mokhtari B, Badalzadeh R, Alihemmati A, Mohammadi M. Phosphorylation of GSK-3 $\beta$ and reduction of apoptosis as targets of troxerutin effect on reperfusion injury of diabetic myocardium. European journal of pharmacology. 2015;765:316-21.

12. Bonventre JV, Zuk A. Ischemic acute renal failure: An inflammatory disease\&quest. Kidney international. 2004;66(2):480-5.

13. Baue AE. The horror autotoxicus and multiple-organ failure. Archives of Surgery. 1992;127(12):1451-62.

14. Koike K, Moore EE, Moore FA, Kim F, Carl VS, Banerjee A. Gut phospholipase A2 mediates neutrophil priming and lung injury after mesenteric ischemia-reperfusion. American Journal of Physiology-Gastrointestinal and Liver Physiology. 1995;268(3):G397-G403.

15. Bakker PJ, Scantlebery AM, Butter LM, Claessen N, Teske GJ, van der Poll T, et al. TLR9 Mediates Remote Liver Injury following Severe Renal Ischemia Reperfusion. PloS one. 2015;10(9):e0137511.

16. Stroo I, Claessen N, Teske GJ, Butter LM, Florquin S, Leemans JC. Deficiency for the Chemokine Monocyte Chemoattractant Protein-1 Aggravates Tubular Damage after Renal Ischemia/Reperfusion Injury. PloS one. 2015;10(4):e0123203.

17. Koksoy C KM, Kuzu I, Ergun H, Gurhan I. Role of tumour necrosis factor in lung injury caused by intestinal ischaemiareperfusion. . Br J Surg. 2001;88:464.

18. Deng J, Hu X, Yuen PS, Star RA. $\alpha$-Melanocyte-stimulating Hormone Inhibits Lung Injury after Renal Ischemia/Reperfusion. American journal of respiratory and critical care medicine. 2004;169(6):749-56.

19. Hamacher-Brady A, Brady NR, Gottlieb RA. The interplay between pro-death and prosurvival signaling pathways in myocardial ischemia/reperfusion injury: apoptosis meets autophagy. Cardiovascular Drugs and Therapy. 2006;20(6):445-62.

20. Nakamura M, Wang N-P, Zhao Z-Q, Wilcox JN, Thourani V, Guyton RA, et al. Preconditioning decreases Bax expression, PMN accumulation and apoptosis in reperfused rat heart. Cardiovascular research. 2000;45(3):661- 70.

21. Hassoun HT, Lie ML, Grigoryev DN, Liu M, Tuder RM, Rabb H. Kidney ischemiareperfusion injury induces caspase-dependent pulmonary apoptosis. American Journal of Physiology-Renal Physiology. 2009;297(1):F125-F37.

22. Oguz E, Yilmaz Z, Ozbilge H, Baba F, Tabur S, Yerer MB, et al. Effects of melatonin on the serum levels of pro-inflammatory cytokines and tissue injury after renal ischemia reperfusion in rats. Renal failure. 2014;37(2):318-22. 
23. Wencker D, Nguyen K, Khine C, Chandra M, Garantziotis S, Ng K, et al., editors. Myocyte apoptosis is sufficient to cause dilated cardiomyopathy. Circulation; 1999: LIPPINCOTT WILLIAMS \& WILKINS 530 WALNUT ST, PHILADELPHIA, PA 19106-3621 USA.

24. Nath KA, Grande JP, Croatt AJ, Frank E, Caplice NM, Hebbel RP, et al. Transgenic sickle mice are markedly sensitive to renal ischemia-reperfusion injury. The American journal of pathology. 2005;166(4):963-72.

25. Campanholle G, Landgraf R, Goncalves G, Paiva V, Martins J, Wang P, et al. Lung inflammation is induced by renal ischemia and reperfusion injury as part of the systemic inflammatory syndrome. Inflammation research. 2010;59(10):861-9.

26. Vilchez D, Ros S, Cifuentes D, Pujadas L, Valles J, Garcia-Fojeda B, et al. Mechanism suppressing glycogen synthesis in neurons and its demise in progressive myoclonus epilepsy. Nature neuroscience. 2007;10(11):1407-13.

27. Johnson L. Glycogen phosphorylase: control by phosphorylation and allosteric effectors. The FASEB journal. 1992;6(6):2274-82.

28. Lees SJ, Franks PD, Spangenburg EE, Williams JH. Glycogen and glycogen phosphorylase associated with sarcoplasmic reticulum: effects of fatiguing activity. Journal of Applied Physiology. 2001;91(4):1638-44.

29. Nielsen JN, Wojtaszewski JF. Regulation of glycogen synthase activity and phosphorylation by exercise. Proceedings of the Nutrition Society. 2004;63(02):233-7.

30. Greenberg CC, Jurczak MJ, Danos AM, Brady MJ. Glycogen branches out: new perspectives on the role of glycogen metabolism in the integration of metabolic pathways. American Journal of Physiology-Endocrinology and Metabolism. 2006;291(1):E1-E8.

31. Puthanveetil P, Wang F, Kewalramani G, Kim MS, Hosseini-Beheshti E, Ng N, et al. Cardiac glycogen accumulation after dexamethasone is regulated by AMPK. American Journal of Physiology-Heart and Circulatory Physiology. 2008;295(4):H1753-H62. 
Ischemia-Reperfusion Injury

\section{Erratum}

In Article "Apoptosis and Histopathology of the Heart after Renal Ischemia-Reperfusion in Male Rat Running title: Ischemia-Reperfusion Injury", with the number of DOI: http://dx.doi.org/10.1590/1678-4324-2017160244, publish in journal Brazilian Archives of Biology and Technology, vol. 60, the page 1.

that read:

${ }^{2}$ Turberculosis \& Lung Research Center, Tabriz University of Medical Sciences, Tabriz, Iran.

Read:

${ }^{2}$ Tuberculosis and Lung Disease Research Center, Tabriz University of Medical Sciences, Tabriz, Iran 